\title{
Managing small populations in practice: black rhino Diceros bicornis michaeli in the Ngorongoro Crater, Tanzania
}

\author{
Anthony Mills, Pete Morkel, Amiyo Amiyo, Victor Runyoro, Markus Borner and Simon Thirgood
}

\begin{abstract}
Black rhino Diceros bicornis michaeli in Ngorongoro Crater, Tanzania were reduced by poaching from c. 110 animals in the mid 1960s to $c .20$ by the mid 1970s. Despite little subsequent poaching the rhino population has not increased. This paper builds on a stakeholder workshop held in September 2003 to consider the problems facing these rhino and make recommendations for management. Research and monitoring is required as conservation decisions are, through necessity, being taken based on expert opinion. Genetic constraints may arise in the future given the small population size. We hypothesize, however, that the rhino population is currently limited
\end{abstract}

by ecological factors including: neonatal predation by hyaena Crocuta crocuta, loss of calving refuges because of a reduction in Acacia xanthophloea, competition for browse with elephant Loxodonta africana and buffalo Syncerus caffer, tick-borne disease, and disturbance from tourism. These factors are exacerbated by an institutional philosophy of non-intervention. We suggest using adaptive inference to assess this hypothesis and to provide managers with appropriate information for rhino conservation.

Keywords Black rhino, Diceros bicornis michaeli, intervention, Ngorongoro Crater, Tanzania.

\section{Introduction}

In the opening chapter of Conservation Biology, Soule (1986) stated that the ultimate test of conservation biology is the application of its theories in management situations'. A black rhino Diceros bicornis standing in the Ngorongoro Crater adorns the cover of this seminal book. The black rhino symbolises the demographic and genetic problems inherent in small populations (Gilpen \& Soule, 1986). The number of black rhino in the Ngorongoro Crater decreased from c. 110 in the mid 1960s to $c .20$ by the mid 1970s as a result of poaching (Borner, 1981). The population has subsequently fluctuated around c. 20 individuals and the last poaching event was in 1995. Monitoring suggests that one male has sired 12 of the current 19 rhino. Genetic constraints are in theory a threat to population viability but there is little evidence of inbreeding depression. It may be unwise to allocate conservation resources to maintaining genetic diversity

\footnotetext{
Anthony Mills ${ }^{1}$, Pete Morkel, Markus Borner and Simon Thirgood ${ }^{2}$ (Corresponding author) Frankfurt Zoological Society, PO Box 14935 Arusha, Tanzania. E-mail s.thirgood@macaulay.ac.uk

Amiyo Amiyo and Victor Runyoro Ngorongoro Conservation Area Authority, P.O. Box 1, Ngorongoro, Tanzania.

${ }^{1}$ Also at: Department of Soil Science, Stellenbosch University, Private Bag X01, Matieland, 7602, South Africa.

${ }^{2}$ Current address: Macaulay Institute, Aberdeen, AB15 8QH, UK.

Received 28 January 2005. Revision requested 6 June 2005. Accepted 4 January 2006.
}

when other threats are more urgent, but these threats need to be prioritized before management strategies can be developed (Caughley \& Gunn, 1996).

The $300 \mathrm{~km}^{2}$ caldera of the Ngorongoro Crater is part of the Ngorongoro Conservation Area, a multiple-use protected area combining conservation with development for the indigenous Maasai (Homewood \& Rodgers, 1991; Thompson, 1997). Most funding for conservation and development is derived from wildlife tourism (Thirgood et al., in press). The Ngorongoro Conservation Area is managed by the Ngorongoro Conservation Area Authority who recognized that a multi-disciplinary approach was essential for rhino management and thus convened a workshop on 3-4 September 2003 to identify conservation threats and recommend management action. The workshop was a mixture of presentations by specialists and discussions in working groups. Threats were identified and prioritized and a conservation action plan was developed for the Crater's black rhino population (Mills et al., 2004). Here we summarize the threats, the uncertainties, and the suggested actions for management.

\section{Conservation threats and management recommendations}

Genetic constraints, stochastic events and metapopulation management

The Crater currently contains 19 rhino: five males (three breeding, one subadult, one calf) and 14 females (six 
breeding, one post-breeding, two subadult, five calves). One male has been dominant since 1993 and has sired 12 of the 19 rhino. Given the small size of the population and the dominance of one male, problems associated with inbreeding depression and loss of genetic diversity may materialize (Ralls et al., 1979). To date, however, there is little evidence of this as the calving age (6.9 years) and inter-calving interval (2.9 years) over 1993-2003 are normal for the species (Emslie \& Brooks, 1999). The sex ratio of the rhino in the Crater is skewed and this is perhaps the primary reason that the population has not declined as a result of high calf mortality. If stochastic events determine that male calves predominate in the future, the population growth rate will decline and the viability of the population would be at risk. Following established guidance for black rhino metapopulation management (Emslie \& Brooks, 1999), it is recommended that breeding males are replaced every generation, female rhino are introduced to increase the population to 20 unrelated adults, and the Crater rhino are linked to the Serengeti rhino through the establishment of a new rhino population in the central Serengeti.

\section{Adult and neonatal mortality}

The population growth rate of the Crater rhino over 1993-2003 was 8.0\% (excluding human-induced mortalities), which is high for black rhino (Emslie \& Brooks, 1999). Adult mortality over $1993-2003$ was $8.3 \%$ with six rhino dying from disease (2), poaching (1-2), injury (1-2) or old age (1). Neonatal mortality over 1993-2003 was between $25 \%$ (minimum based on observed mortality) and $45 \%$ (maximum based on inter-calving intervals). This is high relative to other populations (Emslie \& Brooks, 1999) and may be because of predation by spotted hyaena Crocuta crocuta. Goddard (1967), Van Lawick \& Van Lawick-Goodall (1970) and Kruuk (1972) observed hyaena and lion Panthera leo attacks on rhino calves in the Crater during the 1960s and both predators kill rhino calves in Namibia (Berger \& Cunningham, 1994). Factors that may heighten predation risk on rhino calves include the high densities and large group sizes of hyaena in the Crater and lack of calving refuges for rhino. It is recommended that managers attempt to reduce neonatal mortality by the restoration of forest habitat to provide calving refuges, the reduction of disturbance so that rhino are not displaced from their calves, the provision of carrion to hyaena when rhino calves are vulnerable, and non-lethal intervention when hyaena attack rhino. Adult mortality should be reduced through anti-poaching operations and disease management, and monitoring should establish causes of mortality.

\section{Lerai Forest and elephant}

The Crater is primarily grassland and swamp with the exception of $5 \mathrm{~km}^{2}$ of Lerai Forest Acacia xanthophloea at the base of the northern rim. The forest has declined in area and density since the 1960s, probably as a result of interactions between elephant browsing, tree senescence, water levels and salinity (Western \& Van Praet, 1973; Mills, 2003; Western \& Maitumo, 2004). The forest was a calving area in the 1960s with 17 resident rhino (Goddard, 1966, 1967). Currently the forest is rarely used by rhino, for which the most plausible explanation is that there is less cover and greater competition for browse and disturbance from elephant Loxodonta africana. The restoration of the Lerai Forest as a calving refuge is believed to be critical to the management of rhino in the Crater. This major initiative will require exclusion of elephant using a two strand electric fence that allows the passage of rhino, alternative water sources for tourist lodges on the Crater rim, irrigation to flush salts from the soil (Mills, 2003) and monitoring of forest regeneration. Excluding elephant has restored A. xanthopholea forests in Amboseli and Lewa in Kenya (Western \& Maitumo, 2004).

\section{Fire management and browse}

Ecological change within the Crater since the 1960s, including the decline of the Lerai Forest, reduction in the area of swamps, invasion of exotic weeds such as Bidens schimperi into grassland, and increase in unpalatable shrubs on the Crater rim has reduced browse for rhino (Trollope \& Trollope, 2003). Reduction in browse may cause malnutrition of rhino in the dry season that in turn may increase their susceptibility to disease (Emslie \& Brooks, 1999). Management recommendations to improve browse include restoration of the Lerai Forest, restoration of the swamps by removing drainage ditches, increasing the area of short grassland and control of weeds by fire management, careful burning of the Crater rim to stimulate shrub growth, monitoring to determine which species are utilized by rhino and other browsers, and mapping the distribution of browse species to improve management decisions.

\section{Tick-borne diseases and buffalo}

Two adult rhino died in 2000 from babesiosis exacerbated by poor nutrition following a prolonged drought. Babesia is a protozoan parasite transmitted by the tick Rhipicephalus appendiculatus. Investigation of the abundance of ticks at 33 sites in the Crater demonstrated that ticks were positively associated with the standing crop of grass, and these areas were used mainly by buffalo 
Syncerus caffer (Trollope \& Trollope, 2003). Buffalo have increased in the Crater from $<100$ in the 1960 s to $>4,000$ in 2003 and this has been attributed to the cessation of burning by Maasai pastoralists following their exclusion in 1974 (Runyoro et al., 1995). Whilst black rhino are primarily browsers, forbs such as Trifolium masaiense comprise $50 \%$ of their diet during the wet season (Goddard, 1968) and thus buffalo may compete with rhino for food. Management recommendations to reduce tick-borne disease include implementation of fire management to reduce the area of moribund grassland, and monitoring of the impact of increased fire on vegetation, ticks and buffalo.

\section{Human disturbance}

The Ngorongoro Crater is one of Tanzania's main tourist attractions and in excess of 100 tourist vehicles may visit the Crater in a single day (Thirgood et al., in press). Tourist vehicles have been observed to delay female rhino from returning to calves, which increases the risk of neonatal mortality. The large number of vehicles in the Crater not only disturbs rhino but also compromises the tourism experience. Management should minimize human impacts as much as possible by: controlling the maximum number of vehicles entering the Crater, dispersing tourists to other attractions within the Ngorongoro Conservation Area, offering walking and horse safaris to reduce vehicle pressure, closing unnecessary roads, developing low maintenance roads that reduce damage to vegetation from dust, and monitoring the impact of human disturbance on rhino.

\section{Poaching and security}

The precipitous decline of the Crater rhino during the early 1970s was caused by poaching for horn, and this occurred throughout Tanzania (Borner, 1981). The risk of poaching remains despite the increase in security within the Crater. It is known that dealers in rhino horn were present in the Serengeti region in 2004. Management recommendations are to maintain the present high level of anti-poaching activity, and to monitor and respond to changes in poaching risk.

\section{Philosophy of non-intervention and capacity strengthening}

The threats facing the Crater rhino are primarily anthropogenic and intervention is required to mediate them. The current institutional philosophy of nonintervention could prevent the active management that is necessary for conservation. It is essential that managers understand that deciding not to intervene is as active and important a decision as deciding to intervene. The implementation of the management recommendations described here requires capacity strengthening for Tanzanian conservation professionals.

\section{Discussion}

Although grounded in ecology and genetics, conservation biology is increasingly stressing an interdisciplinary approach (Caughley \& Gunn, 1996; Sutherland, 2000; Borgerhoff-Mulder \& Coppollilo, 2005). This is because the decisions made by managers seldom pertain to models of genetic diversity or population dynamics and are often social, political and economic in nature. Such decisions are often based on imperfect knowledge (Trauger, 1999; Peterson et al., 2003). The recommendations that emerged from the Ngorongoro Rhino Workshop are largely based on expert opinion and untested hypotheses rather than on rigorous research. However, research is required to assess whether replacement of breeding rhino every generation will prevent inbreeding depression, rhino will disperse between populations of a Serengeti metapopulation, elephant browsing and hydrological problems are preventing the regeneration of the Lerai Forest, restoration of the Lerai Forest and intervention with hyaena will increase neonatal survival, elephants and buffalo compete with rhino for browse, fire management will increase availability of browse and reduce the incidence of disease, and tourist disturbance has a negative impact on rhino.

We suggest that these hypotheses should be assessed as part of research based on adaptive inference, whereby multiple lines of reasoning are explored and confirmatory as well as falsification data are sought (Holling \& Allen, 2002). Managers cannot, however, put decisions on hold while researchers attempt to find answers to difficult questions. A more practical approach is to tailor management as a series of experiments whereby methods can be robustly tested. Adaptive inference emphasizes the importance of keeping numerous hypotheses alive and using a wide range of information types to assess the validity of each hypothesis over time. An alternative approach is that of evidence-based conservation, whereby all evidence relevant to the conservation issue under consideration is subjected to a systematic review and decisions are based on the outcome of a meta-analysis (Sutherland et al., 2004). This approach is particularly useful where a substantial research base underpins management, as in medicine where the evidence-based method originated, but it also has the advantage of effectively exposing gaps in knowledge and determining requirements for research (Stewart et al., 2005). 
In the case of the Crater rhino, we suggest that adaptive inference be incorporated into the management strategy, whereby decisions are taken in an iterative manner based on the best available evidence. Decisions need to be reassessed in the light of improved knowledge and changing ecological, financial and political conditions. Metapopulation management of rhino, for example, is dependent not only on the availability of funds for buying and translocating rhino but also on the approval of management authorities. Translocation has been successfully used for rhino metapopulation management in southern Africa and Kenya (Emslie \& Brooks, 1999). In 1998, five rhino were translocated to the Crater from South Africa in an attempt to increase genetic diversity. Two adult rhino subsequently died during a drought in 2000. The cause of death was the tick-borne disease babesiosis and the perception arose that the translocated rhino were carriers of the disease. The political climate changed rapidly, with management authorities unwilling to approve further translocation of rhino. Management inertia developed and during this time the dominant male rhino sired eight calves, thus increasing the risk of inbreeding.

Questions about how much intervention is desirable in an ecosystem such as the Ngorongoro Crater also require attention. Restoration of the Lerai Forest may require the use of electric fencing to exclude elephant or irrigation to remove salts. Intervention to prevent hyaena predation on rhino calves is another controversial issue. In Etosha National Park in Namibia, predation on rhino by lions at waterholes was a management problem and several rhino-killing lions were removed in response (R. Emslie, pers. comm.). Such intervention is not customary in Tanzania where wildlife management has traditionally been less active. However, the ultimate causes of these problems are anthropogenic and thus it could be argued that active intervention is justified. These examples highlight how rhino conservation in the Ngorongoro Crater requires attention in several ways. Ecological conditions need to be managed to enhance the Crater for rhino, security needs to be maintained, intervention philosophies need to be considered, donors need to be approached for funds to purchase rhino, and managers and politicians need to understand the risks associated with loss of genetic diversity. Peterson et al. (2003) advocate scenario planning as a means of assisting conservation decisionmaking. This could be one component but the framework must facilitate information transfer to ensure that decisions are re-evaluated in the light of the best available evidence.

The Ngorongoro Rhino Workshop in September 2003 was the start of an adaptive management process. It was recognized at the time that rhino conservation in
Ngorongoro and more widely in the Serengeti-Mara Ecosystem requires continuous input from managers, scientists and politicians alike. Effective communication and the distillation of information into a format accessible to conservation policy makers are essential. A report from the workshop was sent to all individuals and institutions involved in rhino conservation in Tanzania. A second workshop was held in January 2005 where progress and pitfalls were discussed and a metapopulation management strategy agreed for the black rhino of the Serengeti-Mara Ecosystem.

\section{Acknowledgements}

The Ngorongoro Rhino Workshop was funded by the US Fish and Wildlife Service, African Wildlife Foundation and Frankfurt Zoological Society. We thank the workshop participants for sharing their experience of rhino conservation and Matt Walpole and three reviewers for comments on the manuscript.

\section{References}

Berger, J. \& Cunningham, C. (1994) Black rhino conservation. Science, 264, 757.

Borgerhoff-Mulder, M. \& Coppolillo, P. (2005) Conservation. Princeton University Press, Princeton, USA

Borner, M. (1981) Rhino disaster in Tanzania. Oryx, 16, 59-66.

Caughley, G. \& Gunn, A. (1996) Conservation Biology in Theory and Practice. Blackwell, Oxford, UK.

Emslie, R. \& Brooks, M. (1999) African Rhino. Status Survey and Conservation Action Plan. IUCN/SSC African Rhino Specialist Group, IUCN, Gland, Switzerland.

Gilpin, M.E. \& Soule, M.E. (1986) Minimum viable populations processes of species extinction. In Conservation Biology (ed.

M.E. Soule), pp. 19-34. Sindauer, Massachusetts, USA.

Goddard, J. (1966) Mating and courtship of the black rhinoceros. East African Wildlife Journal, 4, 69-75.

Goddard, J. (1967) Home range, behaviour and recruitment rates of two black rhinoceros populations. East African Wildlife Journal, 5, 133-150.

Goddard, J. (1968) Food preferences of two black rhinoceros populations. East African Wildlife Journal, 6, 1-18.

Homewood, K. \& Rodgers, A. (1991) Masaailand Ecology. Cambridge University Press, Cambridge, UK.

Holling, C.S. \& Allen, C.R. (2002) Adaptive inference for distinguishing credible from incredible patterns in nature. Ecosystems, 5, 319-328.

Kruuk, H. (1972) The Spotted Hyena. Chicago University Press, Chicago, USA.

Mills, A. (2003) Soil Salinity and Dieback of Trees in Lerai Forest. Unpublished report to Frankfurt Zoological Society, Arusha, Tanzania.

Mills, A., Morkel, P., Runyoro, V., Amiyo, A., Muruthi, P., Borner, M. \& Thirgood, S. (2004) Management of Black Rhino in the Ngorongoro Crater. Ngorongoro Conservation Area Authority, African Wildlife Foundation \& Frankfurt Zoological Society, Arusha, Tanzania. 
Peterson, G.D., Cummings, G.S. \& Carpenter, S.R. (2003) Scenario planning: a tool for conservation in an uncertain world. Conservation Biology, 17, 358-366.

Ralls, K., Brugger, K. \& Ballou, J. (1979) Inbreeding and juvenile mortality in small populations of ungulates. Science, 206, 1101-1103.

Runyoro, V., Hofer, H., Chausi, E.B. \& Moehlman, P.D. (1995) Long-term trends in the herbivore population of the Ngorongoro Crater, Tanzania. In Serengeti II (eds A.R.E. Sinclair \& P. Arcese), pp. 146-168. University of Chicago Press, Chicago, USA.

Soule, M.E. (1986) Conservation biology and the real world. In Conservation Biology (ed. M.E. Soule), pp. 1-12. Sinauer, Massachusetts, USA.

Stewart, G., Coles, C. \& Pullin, A. (2005) Applying evidencebased practise in conservation management. Biological Conservation, 126, 270-278.

Sutherland, W.J. (2000) The Conservation Handbook. Blackwell, Oxford, UK.

Sutherland, W.J., Pullin, A.S., Dolman, P.M. \& Knight, T.M. (2004) The need for evidence-based conservation. Trends in Ecology and Evolution, 19, 305-308.

Trauger, D.L. (1999) Can we manage for biological diversity in the absence of scientific uncertainty? In Practical Approaches to the Conservation of Biological Diversity (eds R.K. Baydack, H. Campa III \& J.B. Haufler), pp. 195-202. Island Press, Washington, USA.

Thirgood, S., Mlingwa, C., Gereta, E., Runyoro, V., Malpas, R., Laurenson, K. \& Borner, M. (in press) Paying for conservation: current and future financing scenarios for the Greater Serengeti Ecosystem. In Serengeti III (eds A.R.E. Sinclair, C. Packer, S.A.R. Mduma \& J. Fryxell). Chicago University Press, Chicago, USA.

Thompson, D.M. (1997) Multiple Land Use: The Experience of the Ngorongoro Conservation Area, Tanzania. IUCN, Gland, Switzerland.

Trollope, W. \& Trollope, L. (2003) Prescribed Burning as a Means of Controlling the Incidence of Ticks, the Current Condition of the Lerai Forest and the Infestation of Forbs in the Ngorongoro Crater, Tanzania. Unpublished Report to Frankfurt Zoological Society, Arusha, Tanzania.
Van Lawick, H. \& Van Lawick-Goodall, J. (1970) Innocent Killers. Collins, London, UK.

Western, D. \& Van Praet, C. (1973) Cyclical changes in the habitat and climate of an East African ecosystem. Nature, 241, 104-106.

Western, D. \& Maitumo, D. (2004) Woodland loss and restoration in a savannah park: a 20-year experiment. African Journal of Ecology, 42, 111-121.

\section{Biogeographical sketches}

Anthony Mills is a soil scientist with wide interests in conservation biology. He has conducted research in the Ngorongoro Conservation Area to assess biogeochemical and hydrological processes and their influence on rhino conservation.

Pete Morkel is a wildlife veterinarian who coordinates rhino conservation activities for Frankfurt Zoological Society based at Ngorongoro. He has extensive experience of wildlife capture and has overseen the translocation of $>100$ rhinos in eastern and southern Africa.

Amiyo Amiyo and Victor Runyoro work in the Ecology Department of the Ngorongoro Conservation Area Authority and are responsible for rhino conservation and ecological monitoring within the Crater.

Markus Borner's interest in rhinos dates back to the mid 1970s when he spent 3 years studying Sumatran rhinos. He was subsequently instrumental in monitoring and protecting rhinos in northern Tanzania in the aftermath of the 1970s poaching.

Simon Thirgood has interests at the interface of behavioural, population and community ecology and its application to conservation. He spent 2 years with Frankfurt Zoological Society in the Serengeti where, amongst other activities, he facilitated the development of a metapopulation management strategy for black rhino. 